University of Wollongong

Research Online

Faculty of Business - Papers (Archive)

Faculty of Business and Law

2013

Through the eyes of ex-foster children: placement success and the characteristics of good foster carers

Melanie Randle

University of Wollongong, mrandle@uow.edu.au

Follow this and additional works at: https://ro.uow.edu.au/buspapers

Part of the Business Commons

Research Online is the open access institutional repository for the University of Wollongong. For further information contact the UOW Library: research-pubs@uow.edu.au 


\title{
Through the eyes of ex-foster children: placement success and the characteristics of good foster carers
}

\author{
Abstract \\ Most research focusing on foster placement success or the characteristics of good foster carers is based \\ on the opinions of people currently involved in the foster care system, such as foster carers, social \\ workers or children in care. The few studies which include former foster children usually collect factual \\ (usually quantitative) data to evaluate their pathways or achievements since leaving care, such as \\ educational attainment or employment. This study differs because it examines the perceptions and \\ opinions of adults who were in foster care as children, in relation to the important issues of what \\ constitutes successful foster placement and the characteristics of the foster carers who are most likely \\ to be able to make possible such a placement. For the most part, a successful placement is described by \\ participants in terms of how they feel when they are there - happy, wanted, loved, listened to and safe. As \\ well as the more commonly known characteristics of good foster carers, ex-foster children nominate \\ important attributes as fun-loving, good-listeners and honest. This new perspective adds an important \\ dimension to what we know about foster placement success and should be taken into consideration \\ when making decisions about the delivery of foster care programmes.
}

\section{Keywords}

era2015, children, foster, characteristics, placement, good, ex, eyes, carers, success

\section{Disciplines}

Business

\section{Publication Details}

Randle, M. (2013). Through the eyes of ex-foster children: placement success and the characteristics of good foster carers. Practice: social work in action, 25 (1), 3-19. 
Through the eyes of ex-foster children:

Placement success and the characteristics of good foster carers

\author{
Melanie Randle* $\mathrm{PhD}$ \\ Institute for Innovation in Business and Social Research \\ University of Wollongong \\ Northfields Ave, Wollongong, NSW Australia 2522 \\ mrandle@uow.edu.au
}

* This author is previously unpublished in Practice.

\title{
Biographical Note
}

Melanie Randle is a Senior Research Fellow at the University of Wollongong. Her PhD investigated heterogeneity of volunteering motivations within multicultural communities, and since 2008 her research has focussed on the issue of foster carer recruitment. Melanie's research interests include social marketing and non-profit marketing. 


\section{Through the eyes of ex-foster children:}

\section{Placement success and the characteristics of good foster carers}

\section{SUMMARY}

Most research focusing on foster placement success or the characteristics of good foster carers is based on the opinions of people currently involved in the foster care system, such as foster carers, social workers or children in care. The few studies which include former foster children usually collect factual (usually quantitative) data to evaluate their pathways or achievements since leaving care, such as educational attainment or employment. This study differs because it examines the perceptions and opinions of adults who were in foster care as children, in relation to the important issues of what constitutes successful foster placement and the characteristics of the foster carers who are most likely to be able to make possible such a placement. For the most part, a successful placement is described by participants in terms of how they feel when they are there - happy, wanted, loved, listened to and safe. As well as the more commonly known characteristics of good foster carers, ex-foster children nominate important attributes as fun-loving, good-listeners and honest. This new perspective adds an important dimension to what we know about foster placement success and should be taken into consideration when making decisions about the delivery of foster care programs.

Keywords: foster placement success, foster carer characteristics, ex-foster children 


\section{Through the eyes of ex-foster children:}

\section{Placement success and the characteristics of good foster carers}

\section{INTRODUCTION}

Many studies of foster care refer to the notion of a "successful" foster placement. Some view success in terms of a positive reunification of the child with their original family (Brown \& Campbell, 2007), but perhaps the most commonly agreed requirement for success is placement stability. There is widespread agreement on the disruptive nature of placement moves on foster children (Unrau, Seita, \& Putney, 2008; Webster, Barth, \& Needell, 2000) and placement stability has been linked to a an increased likelihood of positive outcomes for foster children including behavioural well-being (Rubin, et al., 2007), psychosocial wellbeing (Barber \& Delfabbro, 2003) and mental health (James, 2004; Rubin, et al., 2004). Despite the widespread acknowledgement of the benefits of placement stability, anecdotally at least, it is evident that simply lasting the intended duration does not ensure that a placement has been particularly successful in terms of specific outcomes for the child or indeed, successful from the perspective of the foster child.

This has led to a common approach whereby success is measured by specific outcomes for the child. Frequently, these are educational outcomes and studies typically focus on current or former foster children and either having them perform tests for academic achievement (e.g. Fernandez, 2008) or asking a series of questions to ascertain whether they have completed a particular level of education (e.g. Pecora, et al., 2006). A similar approach has been used to gauge outcomes in terms of foster children gaining meaningful employment (see Kerman, Wildfire, \& Barth, 2002). 
Others investigate and report a more broad range of outcomes. For example, Reilly (2003) interviewed 100 former foster children and found that they faced serious challenges when transitioning from the foster care system to independent life, including obtaining and maintaining employment, obtaining adequate health care and avoiding the criminal justice system. Later, Merdinger et al. (2005) conducted a mail survey with 216 former foster youth attending universities in the US and reported outcomes in terms of education, employment, financial resources and social support, physical and mental health, substance abuse, criminal activity and overall life satisfaction. In a similar vein, Fernandez (2008) took a psychosocial approach to examine educational, emotional and behavioural outcomes for foster children. Findings of these multifaceted studies have led to various practical recommendations aimed at increasing placement stability and, in turn, improving long-term outcomes for foster children.

An alternative approach is to have a placement rated by some "objective" party as being successful, and to then describe the characteristics of the placements that fit this description. This approach has identified characteristics of the children likely to be in successful placements - such as being younger, better behaved, more likeable, and wanting to be there (Sinclair \& Wilson, 2003a); system- or agency-related factors usually relating to the level of support provided to the placement (McHugh, et al., 2004); characteristics of the relationship between the child and carer - e.g. the quality of the match, the level of chemistry between the two (Sinclair \& Wilson, 2003a); or personal characteristics of the carers (as will be discussed in the next section).

The issue of permanence and stability has been emphasised as an important factor in successful out of home care (Sinclair, et al., 2007). Achieving such stability has been postulated to necessarily include consideration of factors and relationships both inside and 
peripheral to the foster placement, for example maintaining positive relationships with biological family by including them in planning for the foster child (Holland, Faulkner, \& Perez-del-Aguila, 2005). However, researchers have also emphasised the importance of paying close attention to the views of foster children (Sinclair \& Wilson, 2003b) to ensure that the quest for permanence does not result in the child remaining in a placement where they are obviously unhappy.

There are two points to be made about the studies above. Firstly, the findings from most of these studies focus on the opinions of individuals who are, at the time of fieldwork, involved in the foster care system in some capacity. For example, managers of foster care programs, case workers, foster carers, or the children who are currently in care. The perspective that is absent from many of these studies is of those individuals who have personal experience of being in foster care, but who are now adults. This perspective is valuable because it not only gains the perspective of someone with direct experience of complex foster care arrangements, but also because the individual has matured to the point where they can reflect on their experience, the outcome, and what they feel might have been more appropriate for someone in their situation. In addition, many individuals who were in foster care have formed networks with other foster children - for example through holiday camps or agency social gatherings - and have, to differing degrees, shared their personal experiences with each other. They are therefore able to provide an opinion on most aspects of foster care even if it was not part of their personal experience.

Secondly, where ex-foster children are the source of information for the study, they usually only provide self-reported (usually statistical) information about their current situation or their path after leaving care (e.g. whether they finished high school, if they currently have a job, if they have any substance abuse problems) rather than asking their rather "expert" and 
subjective opinion on their experiences in care and their assessment of their childhood given the benefit of hindsight.

\section{Characteristics of good foster carers}

A number of researchers have attempted to build a profile of those individuals who are likely to be the best foster carers. The result of this is an exhaustive list of personal and familial characteristics. These include, but are not limited to:

- personal characteristics: open-minded and accepting of child's background, tolerant, flexible, easy going, organised, consistent (enforcement of rules), deep love or concern for children, realistic, warm, child oriented, respectful, show love and affection, stable, caring, loving, fair, persistent, committed, trustworthy, able to provide reasonable discipline and set limits (Buehler, Cox, \& Cuddeback, 2003; Cameron \& Maginn, 2008; Crum, 2010; Sinclair \& Wilson, 2003a; Whiting \& Lee, 2003);

- motivations: having the children's welfare as the central motivation, not being motivated by the monetary allowance provided, because of a genuine love for children and young people, (Buehler, Cox, \& Cuddeback, 2003; Sinclair \& Wilson, 2003a); and

- environmental and familial factors: strong marriage or partner, faith and strong support from religious organisations, strong and positive parental support network (Brown \& Campbell, 2007; Buehler, Cox, \& Cuddeback, 2003; Crum, 2010). 
The result of these studies is an extensive list of characteristics for any one foster carer to achieve. In considering this lengthy list of attributes or factors it raises the question of their relative importance and the emphasis that should be placed on finding carers with particular combinations of these characteristics. Again, none of the above studies include adults who were in foster care as children to gain their perspective on the types of people who, in their experience, make the best foster carers.

\section{The voice of ex-foster children}

A number of studies involving former foster children as information sources report on various outcomes, as discussed in previous sections. However these studies simply report on documented or self-report outcomes for these individuals. Few studies focus on the "expert" personal opinions or perceptions of the individuals at the very heart of the complex foster care arrangement - the foster children themselves. There are some notable recent exceptions.

Morris (2007) interviewed 16 former foster children in order to identify the factors that contribute to the low rates of economic independence and self-sufficiency which characterise a high proportion of foster care youth as they age out of the foster care system and transition to independent living. The study identified numerous dominant themes expressed by participants relating to their experiences in foster care and the transition to independent life, for example lacking guidance, financial security and social support. Based on these findings the authors make recommendations for improvements to the foster care system that would make them better prepared for their transition to independent living, such as health education and more real life experiences such as opening a bank account and cooking. Morris makes the point that this important perspective - of former foster children who are now adults - should 
play a central role in the development of policies and programs that improve foster children's ability to transition to adulthood and independent living. However this information source has, to this point, been largely underutilised, seemingly ignored amongst the copious amounts of information that typically feed into government policy development.

In her (2003) book Schofield recounts the experiences of 40 individuals who had been in long-term foster care as children and describes their different pathways to adulthood. She explores various psychological and social factors that contribute to these varied outcomes such as continuity, emotional security, attachment, family relationships, self-esteem and resilience to provide rich insight into the experience of being a foster child and the factors that contribute to such a wide variety of outcomes.

Another recent example is the investigation of former foster children's perceptions of multiple placement moves by Unrau, Seita and Putney (2008). Their findings (for example the negative emotional consequences of placement moves and the impact of this on trust, attachment and relationship building) both support, and add to, prior research on this particular aspect of foster care and the recommendations stemming from these findings have implications for research, policy and practice. They too, note that without understanding how this issue is perceived by adults who have lived through such experiences "any efforts to develop practice or policy solutions are incomplete" (p. 1257).

It is this gap in knowledge that this study seeks to address, by not focussing on one particular aspect of foster care but leaving it open for participants to talk about the aspects of care that they feel was important in the success of a foster care placement.

Specifically, the aims of this study are to understand, from the perspective of ex-foster children: 
1. how a "successful" foster placement is defined and described; and

2. the characteristics of foster carers which enable the achievement of such foster placements.

\section{METHODOLOGY}

\section{Fieldwork Administration}

Eleven in-depth interviews were conducted between July 2009 and June 2010. Participants were recruited through local foster care organisations (CareSouth and CatholicCare) and through the CREATE Foundation - an organisation set up to represent the views of children and young people in, and after, care. In all cases participants were contacted by a member of the relevant foster care organisation and asked if they would be willing to participate in the study. If they gave consent, their details were provided to the researcher, who then contacted each individual to arrange an interview time and place that was convenient to them. Interviews took between 20 and 40 minutes and, with permission from the participant, were recorded and later transcribed. Interviews were conducted in the Illawarra, South Coast, Sydney metropolitan, Central Coast and mid-North Coast regions of New South Wales in Australia.

The fieldwork procedures were approved by the University of Wollongong Ethics Committee. According to the ethics protocol, participants were instructed that it was their opinions as individuals with some experience of the foster care system that we were interested in and they were not under any obligation to disclose personal details about 
themselves. In all cases, however, participants chose to give personal examples of their experiences to support their opinions.

\section{Sample}

The sample for this study consisted of individuals who were over the age of 18 and who had been in foster care as children. Five participants were male and six were female. Participants ranged in age from 18-28 years in order to ensure that their experience with the foster care system was relatively recent. This was important because (1) relatively recent recollections of experiences of the foster care system were required; and (2) beyond about ten years the foster care system was substantially different in terms of the type of care considered optimal for children removed from their biological homes. Participants had been in foster care placements with a range of different agencies, including both government and nongovernment. The number of placements experienced by participants ranged from 1 to 39 .

\section{Measures}

The results reported in this paper are part of a larger study of foster care which also examined other factors such as ex-foster children's views on foster care agencies, the role of caseworkers and public perceptions of foster children. Two questions asked in the interviews form the basis of the research questions addressed here.

\section{Defining a successful foster placement}


Firstly, discussion began with an open-ended question which asked: "Think about a foster placement that you would consider "successful". How would you describe this placement?". This question required an unaided response to ensure that the resulting description incorporated just those elements of the placement that were seen as inherently important to each participant.

\section{Characteristics of good foster carers}

After participants had said all they wanted to say about a successful placement, they were asked: "could you please describe the type of person who you consider to be a particularly good foster carer". Again, participants were not prompted other than to clarify points they had already made, in order not only collect characteristics that were inherently important from their perspective.

\section{Analysis}

Data was managed, stored, analysed and coded by the interviewer because only this person has the contextual knowledge of the interview to interpret the qualitative findings (Rossiter, 2010). NVivo 8.0 was used to manage the data during the manual analysis process. The raw data was grouped into categories with similar themes using the constant comparative method of data analysis (Glaser \& Strauss, 1967). The constant comparative method prescribes that as a first step, incidents be identified within the transcripts. Incidents are statements or comments made by participants that express their opinion or feeling towards the issue being investigated. Secondly, the method requires that categories of incidents be formed. These are 
themes or conceptual categories in the data which are inferred by the analyst. The categories identified form the structure of the following section.

\section{RESULTS}

In order to preserve anonymity of participants, where quotes are provided in this results section any identifying information (for example, age or location of residence) has been omitted from that quote. However, it should be noted that all 11 participants are represented in the quotations used to illustrate the points made in the following sections and where more than one quote is provided to illustrate a point they each come from different participants. As this was an exploratory, qualitative study, results are presented with the aim of reporting the full range of views expressed, not to quantify the number or proportion of participants who expressed any particular view.

\section{Definition of a Successful Placement}

For the most part, answers to this question related to how the ex-foster children felt when they were in a good placement. First and foremost, participants expressed the need to feel genuinely wanted by the carers and other members of the household. They wanted to feel like they belonged in the home and were not simply visiting until another placement could be found. Participants indicated that this was achieved by being treated as a member of the family by carers, and by being given all the rights and responsibilities that would be given to 
the carers' own children, for example, being able to join in on family activities and have friends over like other children did.

“I think the sense that you're part of the family, they don't treat you like you're not one their own children."

Participants described entering foster care and feeling completely disowned and abandoned. They felt like no one wanted them and they didn't really belong anywhere, which was often a result of not only being moved from their home but also their school, circle of friends, and other familiar aspects of the life they knew.

"I think a lot of foster children feel disowned because they're constantly moved from family to family and from school to school and it leaves them feeling like no one wants them and they're just palming them off to other people."

In a related theme, foster children in successful placements felt like they were loved, not only by the primary carer but by the whole household, just like any other member of the family.

"[The child feels] loved, wanted, needed, included."

Ex-foster children also described a good placement as one where they felt safe, where they had what they needed and had people to help them if anything went wrong.

"I think mainly safetywise, it [foster care] helps keep a kid safe and healthy.

Which I think is the main ambition."

Ex-foster children emphasised the importance of feeling like they were listened to by their carers and caseworkers, and that they had some say in the decisions affecting their lives. This was particularly the case as children grew older and wanted to be informed about plans for their future and to have the opportunity to express their own opinions on the matter. 
Participants expressed frustration at being in placements where they felt like they had no control.

“If you don't know what's going on yourself and it's just going on between the carer and the caseworker that's OK, but eventually you get to an age where you want to know about the decision that's being made about your life."

“I didn't feel like they were listening to me. [...] I didn't have control. I couldn't do anything about it. I had to deal with it."

Also important from the perspective of the foster child is for a placement to be stable, where a child does not live with the threat of being moved at any time. Successful placements are those where the child stays in the foster home for as long as required.

"One that's fairly stable, that you're not constantly moving about."

"It's consistent, like it's not short-term, it's long-term."

Overall, participants described a successful placement as one where they felt happy; where they were not burdened with serious worries - such as whether they would be moved to another home again, problems relating to their biological parents or siblings, or being generally unsure about what would happen to them in the future - and where they felt secure, loved and as though they belonged in that home with that foster family. A successful placement meant that they could just relax, have fun and enjoy being a child.

"Happy and looked after and safe."

\section{Characteristics of Good Carers}


Participants were asked specifically to describe the types of people that they felt made good foster carers. The answers given can be divided into the following areas: motivations for being a foster carer; the standard of basic care provided; the home environment, particularly the presence of foster siblings; past experience with children; and personal characteristics.

\section{Motivations}

First and foremost, participants felt that a carers' primary motivation must be a genuine desire to help the foster child and to treat them as a full member of their family. Foster children enter a foster home with feelings of abandonment and dislocation from their previous support networks. Their primary need is to feel like they are wanted and that they belong in their new home, and this is only achieved if the carers and other members of the household genuinely want them there. Foster children are very quick to recognise disingenuous motivations, so if carers do not have the interests of the child as their primary motivation, this will be very quickly identified by that child.

“Genuine care as opposed to some place where you're there for three or four months and you move on to the next place. It feels like they're just waiting to move уои оп...”

Individuals who had been in foster care not only talked about the right motivations for being a foster carer, but also emphasised that some carers are motivated for the wrong reasons. They were quick to identify carers whose primary motivations were financial, rather than the best interests of the child.

"[They are] just doing it for the extra cash. It's probably not much but there's that incentive they're getting paid to look after someone's child." 
Participants also emphasised that the best carers were the ones that had an innate enjoyment of being around and interacting with children. They actually like being in the company of children and did not feel they were a burden in any way.

"More to the fact that they actually enjoy working with kids."

Good carers should not only want to do what is in the best interests of the child, but they should also make foster children feel as though they are loved. They have to have that emotional connection with the child, despite the fact that it may be a temporary arrangement.

"They show the love. [...] Us kids can see when someone really loves us."

\section{Provision of Care}

At a basic level, it was expressed that carers need to provide the fundamental aspects of care and do it well. Washing clothes, making sure the child has good personal hygiene, the correct school uniform, that clothes are ironed and that the child has healthy meals - these were all mentioned as critical to a successful placement. One participant reflected emotionally on their personal experience of a care situation in which this was not the case:

"My school uniform, I was being picked on very badly at school because I had a very small $t$-shirt and only the one. I only got it washed only every two weeks and I wasn't allowed to use the washing machine. They wouldn't buy me deodorant so you had the hot sweaty days at school, you smell so I was classified as the stinky kid. My shoes had holes in them." 
Participants also described good carers as being prepared to do the extra things for their foster children that parents would not think twice about doing for their own children - things that take either a lot of time or money and can be quite draining on the carers over many years.

"They got permission [...] to take us on a [...] holiday around Australia."

This is particularly the case for children that experienced health problems in their youth and required specialised care as part of their upbringing.

"I had a lot of problems myself. ADHD, I had reading problems, I needed glasses, I needed braces. I went to the doctors and had a couple of surgeries and stuff like that and they just treated me as family and they got the things I needed."

In hindsight, grown-up foster children saw the benefits of boundaries and discipline being implemented by carers. While all children at some point push the boundaries of parents, this is perhaps more the case with foster children because they have an ongoing sense that foster carers are not their real parents and so do not have the right to tell them what to do. Participants acknowledged that they felt this way as a child and that at the time they resisted any disciplinary measures undertaken by the carers. However, they also acknowledged that in hindsight it was only through the persistence of good carers that they learned to abide by the rules of the house and live harmoniously under the one roof.

"That's what kids in foster care need, boundaries. I found that when I was at a younger age and a lot of other foster children like me, they say that you're not my parent so I don't have to do what you're telling me to do. They don't see that role model figure, that stern hand type of approach. That's what I think, that they need to set down rules and the child needs to do their best". 


\section{Foster Siblings}

In terms of the household environment, participants also commented on the presence of foster siblings (biological children of the carers). However, in this regard opinions varied. On the one hand, other children in the house were seen to be good company for the foster child and enabled them to socialise and play with other children rather than hanging around the adult carers and/or caseworkers all the time.

“It's better with the kids. It's better because you're not bored, you can talk to somebody, have friends, go off and play.”

On the other hand, it was acknowledged that having other children in the house can be a cause of conflict, particularly if the foster siblings are not supportive of having the foster child in the house. Tension can also result if the foster child feels they are not being treated equally to the biological siblings or if the biological children resent another child taking the parents' attention away from them.

"When there's another child in the placement it is always difficult. [...] All kids are the same, if you live with another kid and they're getting more than you, what are you going to feel? He got a new toy, where the $f^{* * *}$ 's mine?"

It was acknowledged that the issue of foster siblings needs to be assessed on a case-by-case basis. Foster children need to feel welcomed by all members of the foster family and know that they will be treated equally, in terms of rights and responsibilities, as the other members of the household. They need to understand the rules, routines and lifestyle of the household so they have realistic expectations as they enter the family. Similarly, biological children need to feel that the amount of love they receive from their parents is not diminished by the addition of a new family member. 


\section{Experience with Children}

The one qualification or form of experience mentioned as essential for good foster carers was previous experience with children. This does not necessarily need to be experience with foster children; value was also placed on parents who had raised their own children through to adulthood. Participants indicated that even working in child-related industries, such as child care or teaching, could greatly enhance a carer's understanding of children and ways of dealing with them effectively.

It was felt that if this experience was present, then the carers were more likely to understand children and strategies to deal with difficulties or problems (for example, in relation to challenging behaviour or times of emotional stress) effectively. Experience with children also enables carers to recognise typical child behaviour at different ages, thus preventing them from blaming the foster child or labelling them as 'naughty' or 'bad' when they exhibit negative behaviours that are common in most children their age, for example, being deceitful or disobedient.

"[Experience] with foster kids, with their own kids. Even if they've come from working with children whether it be childcare, whether it be teaching."

Therefore, from the child's perspective, carers who had this experience were far better able to relate to children and were less judgemental and quick to dismiss the child as they were more likely to have a good understanding of typical child behaviour.

\section{Personal Characteristics}


Participants were asked to describe the personal characteristics of people who make good carers. Firstly, and as described previously, the best carers were described as being loving and caring. They are people who display love and caring to all around them and for whom the role of parent and nurturer comes as second nature.

"A good carer has to have the abilities of love and treating the child as their own child."

Children in care also considered honesty to be a key trait of good carers; honest to the foster child in terms of expressing any issues or concerns they have, and perhaps even more importantly, honest to the foster care agency in reporting how things are going at home. In some cases, carers would present a picture of happiness to the caseworker when they called or visited, when in fact there was a lot of tension and conflict in the home.

On the other hand, participants reported that when a child raised concerns with teachers or caseworkers and the carer was confronted by the caseworker, the carer would convince them that the child was making up stories or exaggerating the situation and that in fact everything was fine. This scenario would lead to the carer being angry with the foster child because they felt they had made them look incompetent to others. Participants repeatedly emphasised the need to feel like they could trust what carers were saying and that the situation at home would be represented honestly to the foster care agency managing the placement.

“I think they don't want to look as if they're doing something wrong, or they've been caught out doing something. A lot of them can say: 'this kid has made me look stupid, now I'm not happy' and they can turn on the kid themselves."

In a similar vein, good carers have to be good listeners and communicators. Ex-foster children emphasised the importance of feeling that their opinion is valued and that they have 
a voice in the household and some say over their future. Equally, carers who took the time to explain their feelings and the reasons for decisions that affected the child were seen to be more effective than those who did not.

"You can get certain carers who just say: 'look this is the way it is, whatever you think doesn't matter 'cause this is what's right'. Whereas a good carer will say: 'look you're entitled to your opinion and I respect your opinion as long as you respect mine'."

Good carers were also described as being committed to the task of caring for the child and persistent in their efforts to achieve positive outcomes despite the different phases children go through and the challenges that come with them. A genuine commitment to riding the ups and downs to get through to the end was important.

“...if you're going to take on a young child, you gotta be committed. You can't say when the child grows up, it's no longer cute anymore, get rid of it."

Many reflected on their behaviour as foster children as being disrespectful and challenging for the carers, and recalled that despite this, their carers never gave up. They were grateful for such persistence, and expressed their regret for treating their carers badly.

“But I did, I treated her really badly. But when you're a teenager and you're in a really, really bad mood and you're really grumpy and you treat people like crap and you know it but you can't stop it. I was like that all the time."

Importantly, good carers in the eyes of children are those who are not too rigid in their approach and are flexible in the way they manage children. Carers who were overly strict in their rules and routines and did not leave some flexibility to account for different individuals in the home were seen to be less than effective in their role. 
“... a bad carer seems to have an opinion and expect you to acknowledge their ideas and their rules where as a good carer will also want to know how you feel about a situation.”

Good carers were also characterised as being easy going, not too serious and didn't get too stressed about the little things in life.

"Like you can't be a foster parent if you're up tight, it doesn't work out."

Importantly, from the perspective of the child, good carers are fun-loving and have enough time to spend with their foster children. Working was not necessarily a problem for the carerfoster child relationship so long as the carer was able to make the time to participate in meaningful activities with the foster child - for example taking the child out for a milkshake, going to the ice-skating rink or organising and being a part of family activities such as birthday parties or weekend barbeques. Good carers are also there enough to know when the child is having problems at school or needs to talk to someone or ask advice.

“...people that actually have time for the children. Ones that aren't focused on work, they might have a job but they will be there for the children."

Finally, and perhaps most importantly of all, the best carers are those who show understanding for what the child has been through and does not judge them by the circumstances that lead to their being placed in foster care. Many foster children feel that they are either pitied by carers or labelled as bad or naughty children because of the actions of their parents. Foster children do not want pity, but they also do not want to be stereotyped because of their background. Good carers are empathetic to their situation and are also understanding of the need for foster children to have contact with their birth families. 
"I guess that they're accepting about the fact that you had to [...] go and see [your birth parents] every so often, they were quite accommodating to that."

\section{Overall}

The impact on ex-foster children of being placed with carers who exhibited all the qualities described above cannot be overstated. Participants described how they felt when they were finally placed with good carers, and the difference this made not only to their feelings of security and self-confidence, but to their performance at school, their ability to make friends and socialise, and their general optimism for the future.

“...when I finally got a really great carer I loved it. I picked my grades up, I got better at school, I learnt how to dress myself properly, my hygiene got better because I was more confident with myself...”

\section{CONCLUSIONS}

For the most part, the definition of a successful foster placement from the perspective of exfoster children relates to how the children feel when they are there. Happy, wanted, safe, loved and listened to. This is certainly not to discount the definitions used in previous studies - such as reunification (Brown \& Campbell, 2007) or specific and measurable outcomes such as the child's health (Rubin, et al., 2004). However one can presume that if all of the children's criteria for success as highlighted in this study are achieved, then it is more likely that the other measures of success would naturally follow. The perspective of ex-foster 
children is important here because in Buehler's (Buehler, Cox, \& Cuddeback, 2003) study of the factors that carers feel contribute to a successful placement, findings primarily related to the cares themselves, how they feel and the familial factors that contribute a successful placement. Very little was mentioned about how foster children feel when they are in a good placement, which was central to the definition provided by former foster children. If nothing else this definition should be cause for pause and contemplation for foster care practitioners and policy makers in terms what can be done to ensure that these emotional outcomes for children can be best achieved within the foster care systems currently in place.

In relation to the characteristics of successful foster carers, a number of similarities can be drawn between the results of this study and previous investigations. This is particularly the case in terms of personal characteristics - including loving and caring, easy going and not too serious, committed and persistent, understanding and non-judgemental flexible (Buehler, Cox, \& Cuddeback, 2003; Sinclair \& Wilson, 2003a). Other attributes are particularly relevant from the foster child's perspective, such as honest (in terms of being honest not only with the foster child about decisions that affect them, but also honest with caseworkers about how things are going within the foster home); being good listeners and communicators (being able to genuinely listen to the views and opinions of the foster child and clearly explain the rationale for decisions that affect them); and fun-loving (genuinely enjoying spending time doing things children like to do, and not being too focused on the more serious aspects of life such as work).

In practice, the issue of attracting enough suitable individuals to become foster carers has been one of the key challenges facing foster care agencies in recent times. Insights into the types of people likely to be capable of providing high quality foster care are invaluable in developing effective marketing and communications strategies that specifically target these 
types of individuals. The present findings add to current knowledge regarding the qualities that make successful foster carers from an alternative perspective - ex-foster children. In addition, findings can also be used by practitioners to inform screening and selection processes in terms of the qualities they look for in potential foster carers, for example motivations for becoming a carer, personal characteristics and family and home environment. Considering these results in developing strategies for recruitment and selection will ensure that the important perspective of the foster child is not ignored.

In addition it should be remembered that the questions used to elicit answers to the research questions posed for this study were unprompted. The result of this is that only those factors or characteristics that are inherently important to participants are included in the results, which provides some guidance as to their relative importance in amongst the voluminous information previously collected on both of these issues (for example, the extensive list of carer attributes that accumulates when the results of all previous studies are combined). In some of these previous studies (e.g. Brown \& Campbell, 2007) participants are given a long list of possible carer characteristics which, because they are almost exclusively positive, not surprisingly all achieve relatively high levels of agreement by respondents.

The value of the perspective of ex-foster children has been emphasised in this paper, however the potential limitations of this data source should also be noted. Any participant who is interviewed on their past experiences is asked to reflect and call on their memory of particular events and so it is possible that participants' views on their time in foster care could be influenced by their subsequent experiences or learnings. In addition, it should be noted that this was a relatively small-scale, geographically localised study designed to gain insight into the views of ex-foster children and was not intended to be representative of the population of individuals who have experienced foster care. 
This study was conducted in order to add to current knowledge in the areas of the definition of placement success and the types of people who are most likely to be able to provide this type of foster placement. It is not suggested that this should override previous findings, however it is suggested, in chorus with Unrau's (2008) view, that any attempt to develop policy or practice without consideration of the important perspective of ex-foster children is left wanting. 


\section{References}

Barber, J. G., \& Delfabbro, P. H. (2003). Placement Stability and the Psychosocial WellBeing of Children in Foster Care. Research on Social Work Practice, 13(4), 141-151.

Brown, J. D., \& Campbell, M. (2007). Foster parent perceptions of placement success. Children and Youth Services Review, 29(8), 1010-1020.

Buehler, C., Cox, M. E., \& Cuddeback, G. (2003). Foster Parents' Perceptions of Factors that Promote or Inhibit Successful Fostering. Qualitative Social Work, 2(1), 61-83.

Cameron, R. J., \& Maginn, C. (2008). The Authentic Warmth Dimension of Professional Childcare. British Journal of Social Work, 38(6), 1151-1172.

Crum, W. (2010). Foster parent parenting characteristics that lead to increased placement stability or disruption. Children and Youth Services Review, 32(2), 185-190.

Fernandez, E. (2008). Unravelling Emotional, Behavioural and Educational Outcomes in a Longitudinal Study of Children in Foster-Care. British Journal of Social Work, 38(7), $1283-1301$.

Glaser, B. G., \& Strauss, A. L. (1967). The Discovery of Grounded Theory. Chicago: Adline.

Holland, S., Faulkner, A., \& Perez-del-Aguila, R. (2005). Promoting stability and continuity of care for looked after children: a survey and critical review. Child and Family Social Work, 10(1), 29-41.

James, S. (2004). Why do foster care placements disrupt? An investigation of reasons for placement change in foster care. Social Service Review, 78(4), 601-627.

Kerman, B., Wildfire, J., \& Barth, R. P. (2002). Outcomes for Young Adults who Experienced Foster Care. Children and Youth Services Review, 24(5), 319-344.

McHugh, M., McNab, J., Smyth, C., Chalmers, J., Siminski, P., \& Saunders, P. (2004). The Availability of Foster Carers: Main Report. Retrieved from 
http://www.sprc.unsw.edu.au/media/File/Report12_04_Avail_of_Foster_Carers_Main $\underline{. \mathrm{pdf}}$

Merdinger, J. M., Hines, A. M., Osterling, K. L., \& Wyatt, P. (2005). Pathways to College for Former Foster Youth: Understanding Factors That Contribute to Educational Success. Child Welfare, 84(6), 843-866.

Morris, R. (2007). Voices of Foster Youths: Problems and Ideas for Change. Urologic Nursing, 27(5), 419.

Pecora, P. J., Williams, J., Kessler, R. C., Hiripi, E., O’Brien, K., Emerson, J., et al. (2006). Assessing the educational achievements of adults who were formerly placed in family foster care. Child and Family Social Work, 11(1), 220-231.

Reilly, T. (2003). Transition from care: status and outcomes of youth who age out of foster care Child Welfare, 82(6), 727-746.

Rossiter, J. R. (2010). Measurement for the Social Sciences: The C-OAR-SE Method and Why it Must Replace Psychometrics. London: Springer.

Rubin, D. M., Alessandri, E. A., Feudtner, C., Mandell, D. S., Localio, A. R., \& Hadley, T. (2004). Placement Stability and Mental Health Costs for Children in Foster Care. Pediatrics, 113(5), 1336-1341.

Rubin, D. M., O'Reilly, A. L. R., Luan, X., \& Localio, A. R. (2007). The Impact of Placement Stability of Behaivoural Well-being for Children in Foster Care. Pediatrics, 119(2), 336-344.

Schofield, G. (2003). Part of the family: Pathways through foster care. London: BAAF.

Sinclair, I., Baker, C., Lee, J., \& Gibbs, I. (2007). The Pursuit of Permanence: A Study of the English Child Care System. London: Jessica Kingsley.

Sinclair, I., \& Wilson, K. (2003a). Foster placements: Why they succeed and why they fail. British Journal of Social Work, 33(7), 871-884. 
Sinclair, I., \& Wilson, K. (2003b). Matches and mismatches: The contribution of carers and children to the success of foster placements. British Journal of Social Work, 33(3), 871-884.

Unrau, Y. A., Seita, J. R., \& Putney, K. S. (2008). Former foster youth remember multiple placement moves: A journey of loss and hope. Children and Youth Services Review, $30(11), 1256-1266$.

Webster, D., Barth, R. P., \& Needell, B. (2000). Placement Stability for Children in Out-ofHome Care: A Longitudinal Analysis. Child Welfare, 79(5), 614-632.

Whiting, J. B., \& Lee, R. E. (2003). Voices from the system: A qualitative study of foster children's stories. Family Relations, 52, 288-295. 